\title{
On the pattern of change in peripheral nerves produced by isoniazid intoxication in rats
}

\author{
J. B. CAVANAGH \\ From the M.R.C. Research Group in Applied Neurobiology, \\ Institute of Neurology, Queen Square, London
}

Pegum (1952) first reported in a letter to the Lancet that patients on isoniazid (isonicotinic acid hydrazide, I.N.H.) therapy might suffer from peripheral neuropathy. This observation was subsequently confirmed by Jones and Jones (1953), by Gammon, Burge, and King (1953) and by Biehl and Skavlem (1953). It became clear from the work of Biehl and Vilter (1954) that high doses of isoniazid $(20 \mathrm{mg}$. $/ \mathrm{kg}$./ day) regularly produced symptoms of neuritis in patients, that their excretion of vitamin $B_{6}$ under isoniazid medication rose to three times the normal rate and that large doses of pyridoxine were fully protective against developing neuropathy. The action of isoniazid had already been shown to be competitive against the phosphorylation of pyridoxine and its inhibitory action upon microorganisms was competitively reversed, particularly by pyridoxamine and by pyridoxal (Boone and Woodward, 1953; Lichstein, 1955). The reason for the occurrence of only $40 \%$ incidence of neuritis in patients on a high daily dose of isoniazid became clear when it was shown by Biehl $(1956 ; 1957)$ that, on the basis of finding a bimodal distribution of the percentage of administered isoniazid found free in the urine, patients could be divided into two clear groups, slow inactivators and rapid inactivators. Mitchell, Riemensnider, Harsch, and Bell (1958) suggested that this polymorphism for isoniazid metabolism might be genetically determined, and evidence in support came from Harris, Knight, and Selin (1958) who found a much higher incidence of rapid inactivators amongst Japanese than amongst Caucasians. This idea has been confirmed by Evans, Manley, and McKusick (1960), who showed that the slow inactivator state is recessive, and that a 'dosage' effect of the allele controlling the dominant character can be demonstrated. Polyneuritis tends to occur more frequently in slow inactivators than in rapid inactivators (Biehl, 1957).

The nature of the changes in human peripheral nerves is not well understood and only two cases in which post-mortem studies have been done have been reported (Zbinden and Studer, 1955a). The only changes noted were Wallerian degeneration in peripheral nerves. The spinal cord and brain in each case appeared normal. Zbinden and Studer (1955b) made an experimental study using rats, rabbits, and guineapigs. The first species regularly showed degeneration of peripheral nerves within 15 days of being on a diet containing $250 \mathrm{mg} . / \mathrm{kg}$. of isoniazid. Functional disturbances did not appear, however, until after seven to eight months of continuous dosing. They found that pyridoxine $(50 \mathrm{mg}$./day) and pyridoxal phosphate both had a significant effect in mitigating the severity of the changes, whereas other vitamins of the B group had none. Neither guinea-pigs nor rabbits showed significant peripheral nerve lesions.

Schlaepfer and Hager (1964a, b, c) have studied various ultrastructural features of the peripheral nerve degeneration in rats. In the early stages the changes in sciatic nerve showed granularity of axoplasm and mitochondrial swelling which are indistinguishable from those found in early Wallerian degeneration (Vial, 1958). It is thus clear that isoniazid produces degeneration of Wallerian type in rats and in man and that the clinical evidence suggests that recovery, presumably by reinnervation, is the rule. It is also apparent that the spinal cord and central nervous system generally are not significantly affected and in this respect the pattern of the process would seem to be different from that found in organo-phosphorus neurotoxicity (Cavanagh, 1954; 1964a, b; Cavanagh and Patangia, 1965). On the other hand evidence has been put forward suggesting that the neuropathy that complicates acute intermittent porphyria is also different from that due to organo-phosphorus compounds (Cavanagh and Mellick, 1965). The purpose of this study is to determine whether or not isoniazid neuropathy resembles either of these two patterns of neurological disease.

MATERIALS AND METHODS

Three groups of Wistar male rats were used.

GROUP I Adults (12) weighing 270 to $300 \mathrm{~g}$. were fed on 
powdered chardex to which $0.25 \%$ isoniazid was added (calculated dose $250 \mathrm{mg}$./kg./day).

GROUP II Young male weanling rats (12) averaging $68 \mathrm{~g}$. were fed on the same powdered diet containing $0.25 \%$ isoniazid (calculated dose $250 \mathrm{mg}$./kg./day).

GROUP III Young male weanling rats (8) averaging $73 \mathrm{~g}$. were fed on a normal (chardex) diet and given isoniazid in saline subcutaneously at $250 \mathrm{mg}$. $/ \mathrm{kg}$./day, half in the morning and half in the evening.

The animals were weighed and examined regularly, and were killed with an overdose of ether at various times. The chest was opened before the heart stopped beating and, through a cannula passed into the aorta from the left ventricle, formal saline was perfused after a short preliminary perfusion of normal saline to wash out blood from the circulation.

Central nervous tissue was dissected out after perfusion fixation. Blocks were taken from sciatic nerve, lumbar spinal root ganglia, lumbar, thoracic, and cervical spinal cord, from brain-stem and cerebellum, and from cerebrum. They were embedded in paraffin, cut at $10 \mu$, and stained with haematoxylin and eosin, cresyl fast violet, and Glees and Marsland's stain for nerve fibres.

Blocks of muscles were taken from anterior tibial and posterior tibial groups, from the quadriceps femoris and adductors and from psoas muscles. About six frozen sections at $50 \mu$ were made of each of these and stained with sudan black B and carmalum (Cavanagh, Passingham, and Vogt, 1964) or by Glees and Marsland's method for axons.

The posterior tibial nerve above the ankle and the saphenous nerve were laid on a library card and fixed in Flemming's solution for fibre diameter measurements after photography at a magnification of 1,000 diameters. The measured fibres were placed into $2 \mu$ groups.

In a few animals, portions of peripheral nerve were teased in $30 \%$ glycerin in water under a dissecting microscope to confirm that only Wallerian degeneration was present.
RESULTS

FUNCTIONAL DISTURBANCES One of the earliest changes shown by both adult and weanling rats on a diet containing $0.25 \%$ isoniazid is failure to maintain the normal weight gain which continues so long as the diet is given (Figs. 1 and 2). Whether this is directly due to the isoniazid is uncertain since weanling rats given the same daily quantities of isoniazid subcutaneously gain weight at the same rate as normal weanling rats of the same sex (Fig. 2). Nonetheless, these injected animals (group III) develop peripheral nerve changes at the same time and apparently to the same degree as the animals in group II on dietary isoniazid. It is possible, since the alimentary tract in animals receiving I.N.H. in their diet is directly exposed to high concentrations of this substance, that its inhibitory action upon aminoacid transport may be more profound than after subcutaneous administration. Munck (1965) has shown that 4-deoxypyridoxine equally inhibits hydroxyproline, arginine, and threonine transport through the gut wall. Since these are the three known amino-acid transport systems through the intestinal wall, it is probable, a priori, that isoniazid in such high doses would have a marked effect upon aminoacid absorption. This suggestion may help towards explaining the failure of weight gain with oral isoniazid as compared with the normal weight gain in injected animals.

Signs of paresis were difficult to find. Despite careful observation and testing no abnormality in limb function was found in any of the weanling rats during the 11 weeks on I.N.H. However, wasting of the hind limbs was noted in some of the animals after five weeks on the drug. This contrasts strangely with the

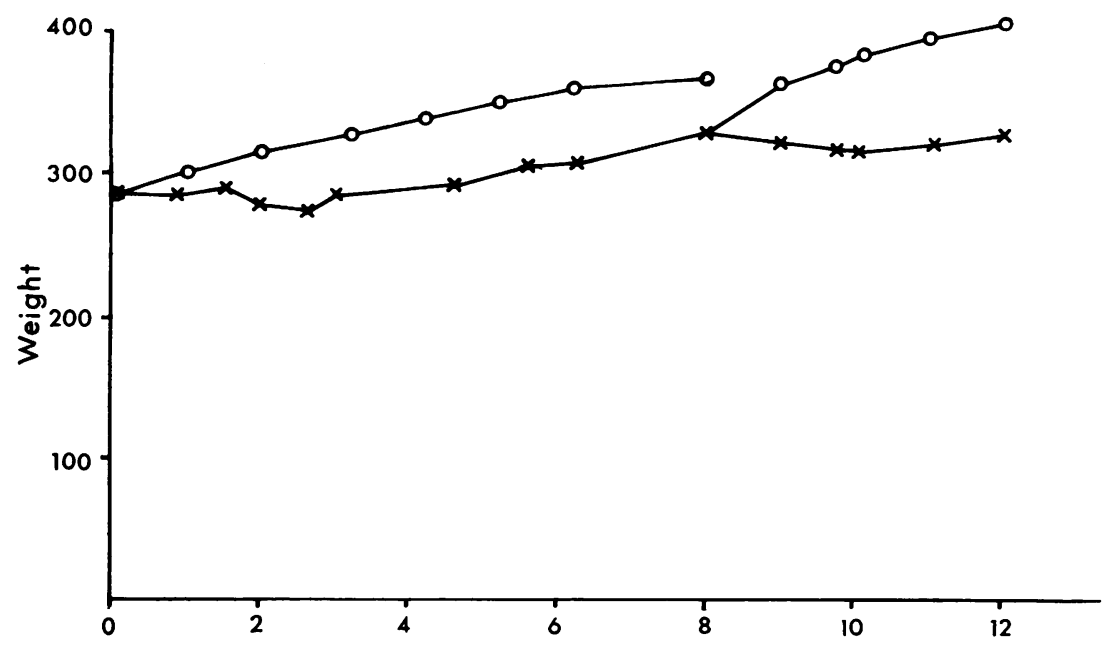

FIG. 1. Weight curve of adult rats fed on a diet containing $0.25 \%$ I.N.H. Ordinate, weight in grams. Abcissa, time in weeks. $0-0$ rats on normal diet. $x-x$ rats on $I . N . H$. diet. 


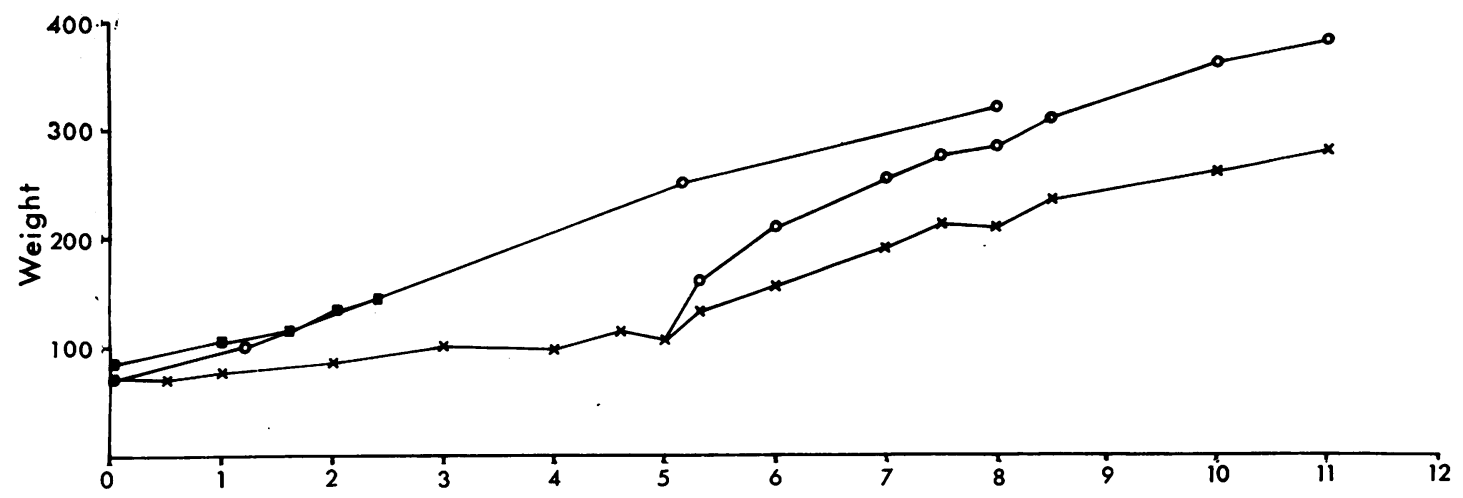

FIG. 2. Weight curve of weanling rats fed on a diet containing $0 \cdot 25 \%$ I.N.H. Ordinate, weight in grams. Abcissa, time in weeks. 0-0 rats on normal diet. $x-x$ rats on $I . N . H$. diet. $\square-\square$ rats with $250 \mathrm{mg} . / \mathrm{kg}$. I.N.H. daily.

severe changes in peripheral nerves, particularly in muscles, that were found in animals killed after only three weeks on the diet.

The animals in group III given subcutaneous I.N.H. began to show weakness of the hind limbs after three weeks. This was accompanied by mild diarrhoea and mild wasting of the hind limbs.

The adult animals in group I began to show weakness and loss of control of hind limbs after eight weeks on I.N.H., but never developed severe weakness or wasting. This absence of functional disturbance again contrasts strangely with the structural changes found after only two weeks in nerves and muscles. These observations accord with those of Zbinden and Studer (1955b) who found no functional disturbances until seven months on the I.N.H. diet.

STRUCTURAL CHANGES IN ADULT RATS Even after two weeks on the I.N.H. diet the sciatic nerves showed severe and extensive Wallerian type degeneration of nerve fibres. Teased preparations of sciatic nerves from these animals and from others at no time showed segmental myelin degeneration, and axon degeneration appeared contemporaneously with myelin fragmentation.

Anterior horn cells and sensory root ganglion cells showed no abnormalities, but the ventral spinal roots showed many degenerating nerve fibres (Fig. 3). None were, however, present in dorsal spinal roots.

The frozen sections of anterior tibial and gastrocnemius muscles showed severe and widespread fragmentation of motor nerve fibres. Some nerve bundles showed almost complete denervation (Fig. 4). The remaining intact nerve fibres were usually of large diameter $(10$ to $12 \mu)$. Muscle spindles showed loss of fine motor fibres, but invariably the large

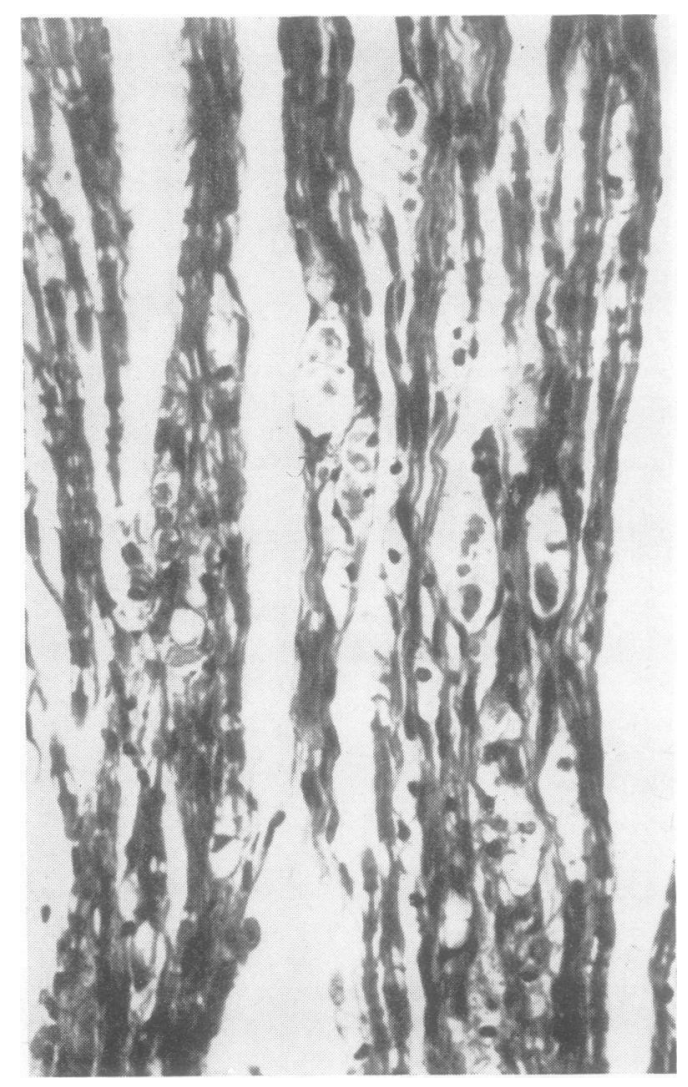

FIG. 3. Ventral lumbar spinal root in rat 40 days on I.N.H. diet. Extensive Wallerian degeneration present. The adjacent dorsal spinal root was normal. Haematoxylin and eosin $\times 250$. 


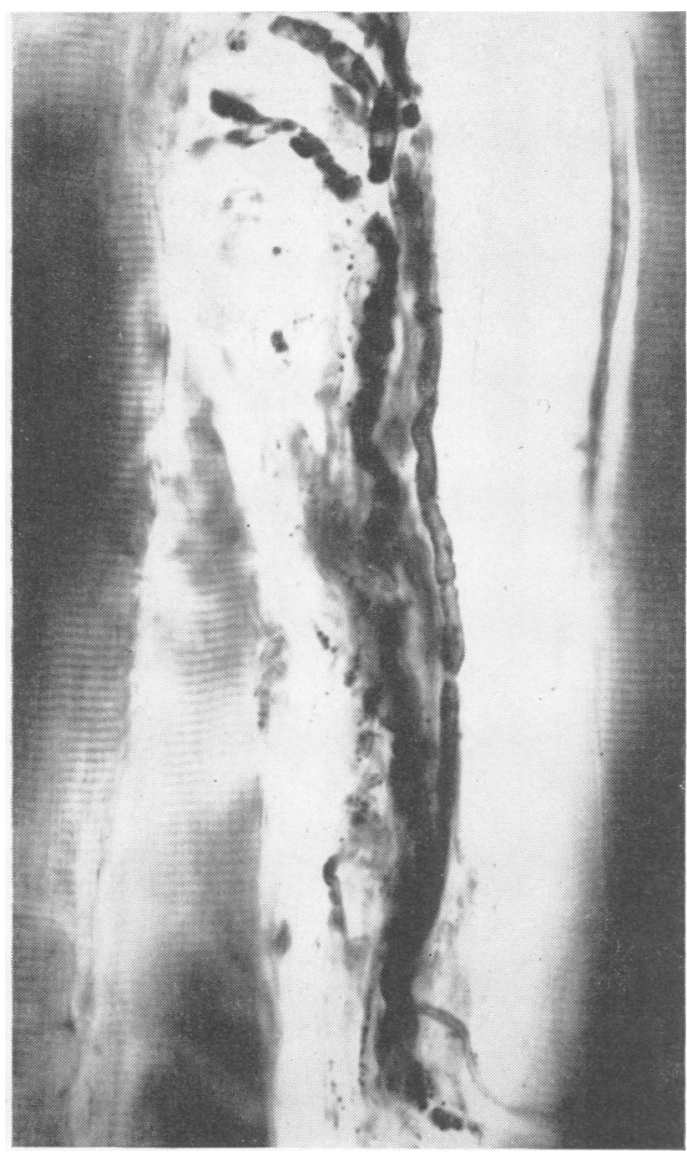

FIG. 4. Intramuscular nerve bundle in gastrocnemius muscle showing severe loss of fibres. I.N.H. for 51 days. Sudan black $B \times 350$.

diameter primary sensory fibres were preserved and their naked annulo-spiral formations stained up clearly in Sudan black B preparations. Very few normal fibres to Golgi tendon organs were found, although in these muscles normally they can be readily identified in Sudan black B preparations.

Transverse sections of paraffin-embedded muscle showed slight general diminution in muscle fibre size. In the quadriceps femoris and in adductor muscles, the same general pattern of denervation existed, not quite so severe as in the more distal muscles. Again large diameter fibres tended to survive in the intramuscular nerve bundles and similar sized fibres persisted in muscle spindles. A few normal fibres to Golgi tendon organs were seen. Many very fine collateral sprouts were present in both these muscles springing from surviving nerve fibres.

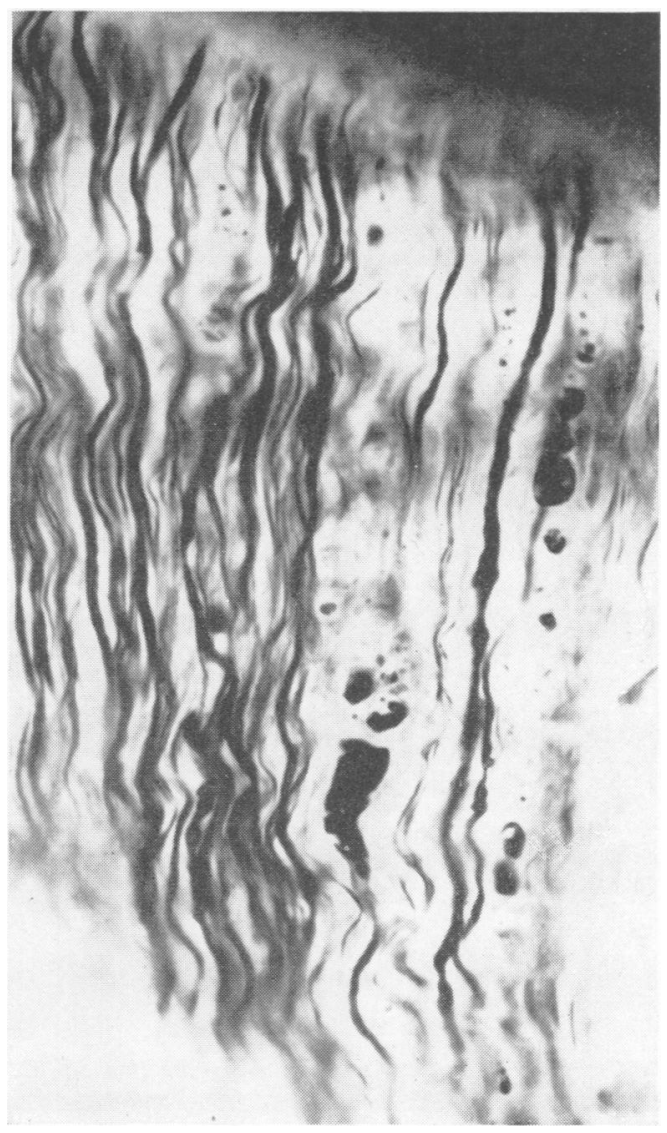

FIG. 5. Intramuscular nerve bundle in tibialis anticus muscle showing fragmentation of a few fibres and very many fine unmyelinated (regenerating) fibres. I.N.H. for 61 days. Glees and Marsland $\times 390$.

Sections of psoas muscle by contrast showed only slight degeneration of occasional motor nerve fibres. Most of the intramuscular nerve bundles remained intact and many normal Golgi tendon organs and muscle spindle fibres were found. Very few collateral sprouts were found in this muscle.

The same pattern of nerve fibre change was found in animals killed in 18 days, 40 days, 61 days, and 89 days. At 18 days and subsequent days collateral sprouting became a very marked feature of the axonstained muscle preparations from above and below the knee (Figs. 5 and 6). The psoas muscle, by contrast, consistently showed very little active degeneration and only a few collateral sprouts. Anterior tibial and gastrocnemius muscles tended to show more advanced and extensive changes than the quadriceps femoris and adductor muscles. In all these 


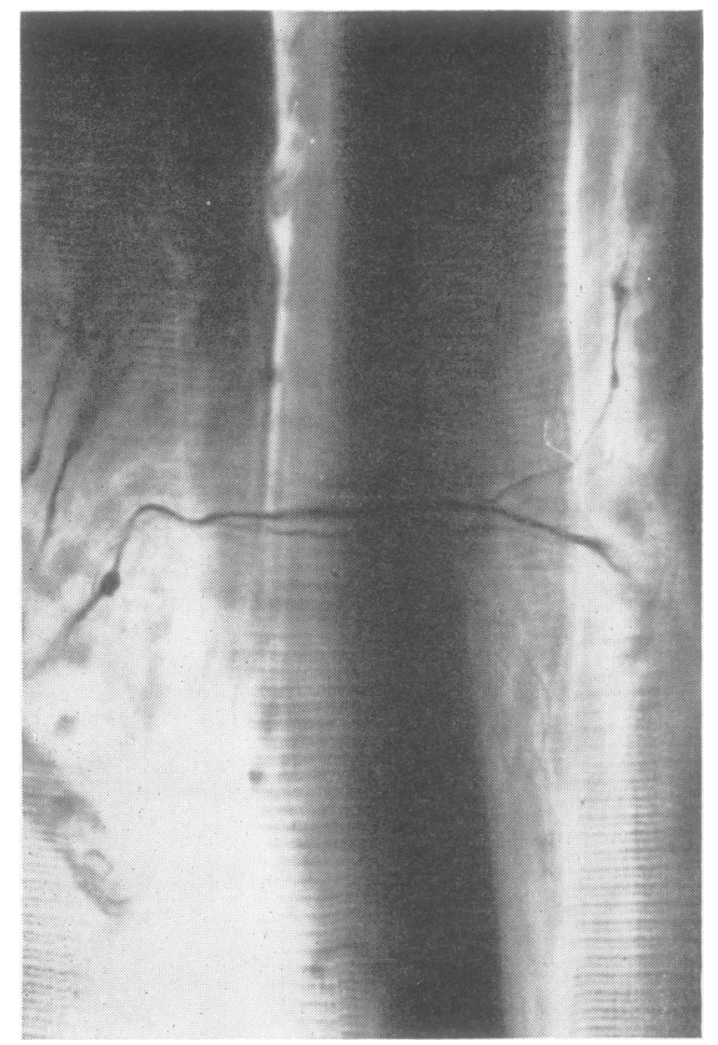

FIG. 6. Fine collateral sprouts with swelling in tibialis anticus muscle. I.N.H. for 61 days. Glees and Marsland $\times$ 350.

preparations muscle spindles constantly showed normal intact primary sensory fibres and stainable annulo-spiral formations (Fig. 7). Normal Golgi tendon organs by contrast were scarcely ever found in these muscles. At these later stages Wallerian degeneration was frequently present in the ventral roots but only occasionally in the dorsal roots in the 61- and 89-day animals. In both these and in animals put back onto a normal diet definite signs of activated neuroglia in the posterior spinal tracts were found. No degeneration, however, was seen in either anterior horn cells or in spinal root ganglia, other than occasional vacuolation of doubtful significance.

REGENERATIVE ACTIVITY Two animals were put back onto a normal diet after $\mathbf{4 4}$ days, and killed after a further 17 and 45 days respectively. The 17-day recovery animal showed definite degeneration in the gracile tracts of the spinal cord. A very occasional degenerating fibre was found in the dorsal spinal roots and many in the ventral roots. In the muscles there was a profusion of collateral sprouts and fine

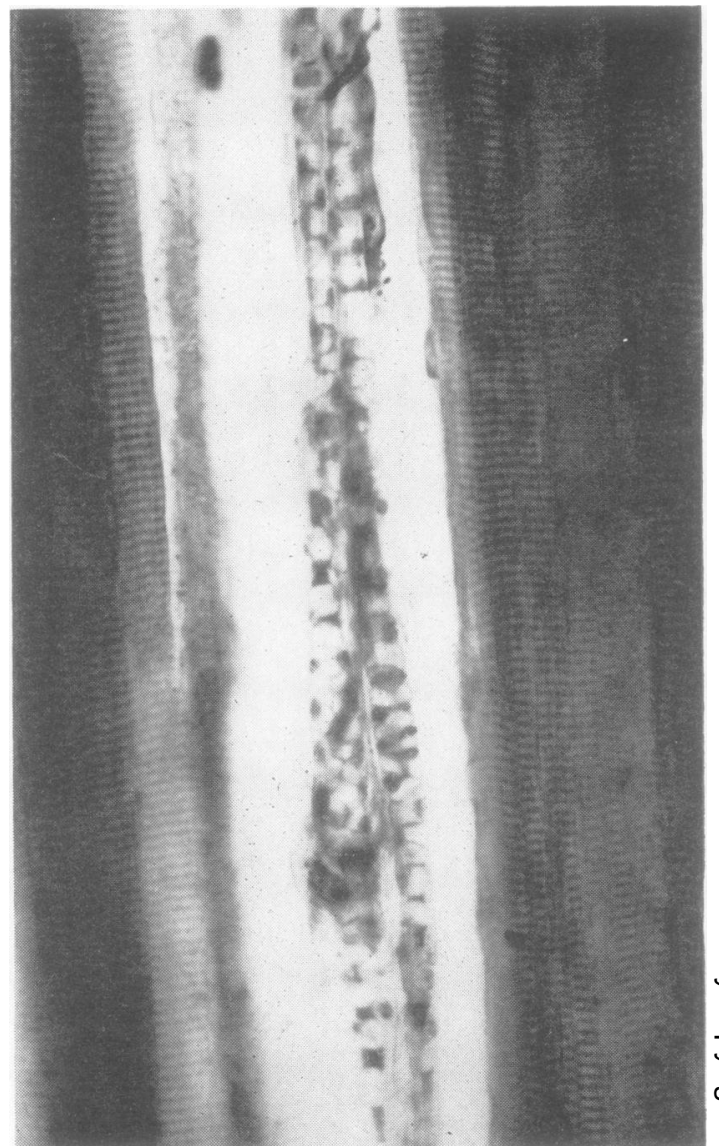

FIG. 7. Normal muscle spindle in otherwise severely denervated tibialis anticus muscle. Note the black staining terminal nerve fibres coiled around the equatorial region. These disappear on denervation. Myelinated fibre out of focus. Sudan black B-carmalum $\times 320$.

fibres in the intramuscular nerve bundles and spreading out over the muscle fibres. Single large diameter fibres were also present and again sensory fibres of muscle spindles were normal. After $\mathbf{4 5}$ days on a normal diet the picture had changed so that very little myelin debris now remained but there was a profusion of collateral sprouts through the muscles above and below the knee. More fibres were to be found in silver-impregnated than in Sudan-black-Bstained preparations so that most of these newly grown fibres had not yet remyelinated. Psoas muscles in both these animals appeared normal.

STRUCTURAL CHANGES IN WEANLING RATS The two animals killed at 25 days showed widespread denervation of the tibialis anticus and gastrocnemius muscles with much collateral sprouting. Two 

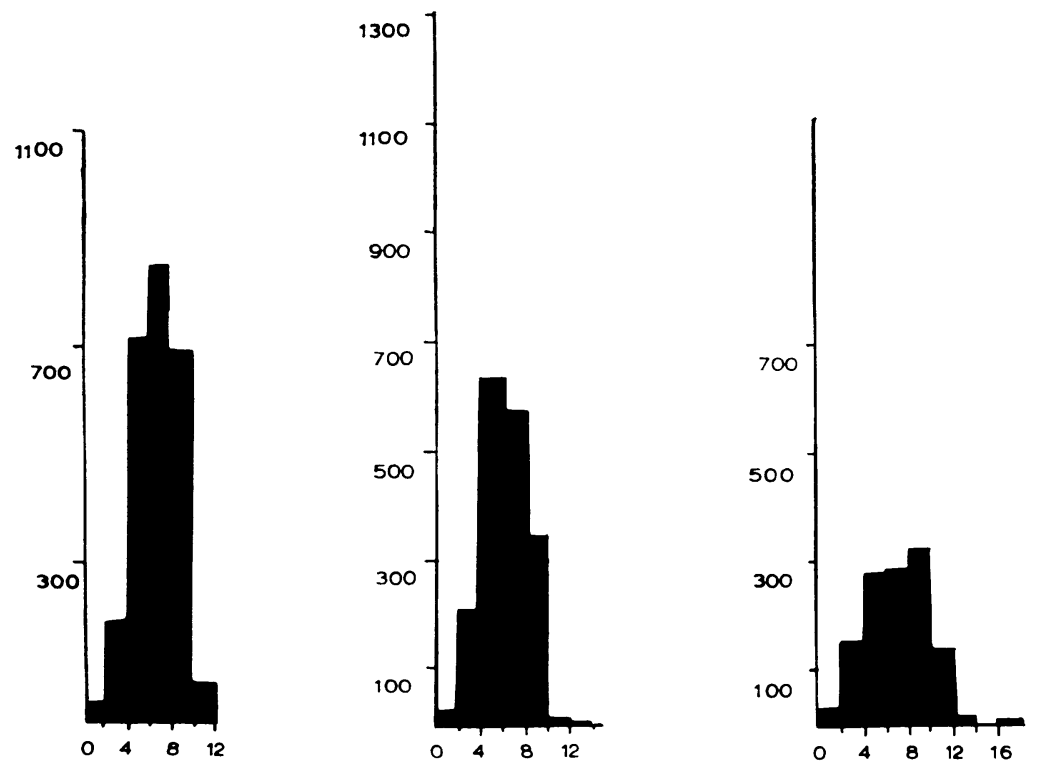

FIG. 8. Histograms of fibre diameter spectra of posterior tibial nerves from normal rat (left) and from rats on I.N.H. diet for three weeks (middle) and seven weeks (right). Ordinate, numbers of fibres: abcissa, fibre diameter in $\mu$.

animals killed at five weeks showed very severe to almost complete denervation of muscles below the knee, and rather less severe change in muscles above the knee. In all muscles primary sensory fibres to muscle spindles were found intact, and collateral sprouts from other surviving fibres were numerous.

In one animal killed at seven weeks very severe denervation occurred below the knee and in quadratus femoris. Psoas muscle was, however, almost normal. Another animal killed at seven weeks after being on a normal diet for two weeks showed severe denervation atrophy of muscle fibres below the knee and milder atrophy above. The psoas was almost normal. Very large numbers of collateral sprouts, many with conspicuous swellings on them, were found in the quadriceps femoris and in tibialis anticus muscles.

FIBRE DIAMETER STUDIES IN POSTERIOR TIBIAL NERVES (FIG. 8) There is a unimodal distribution of fibre diameters in this mixed nerve with a peak frequency in the adult rat $(300 \mathrm{~g}$.) at 7 to $8 \mu$ external diameter.
It is rare to find fibres above $12 \mu$. After three weeks on I.N.H. there was a reduction in the total numbers of fibres (Table I) which continued to fall in the six and seven week samples. The reduction appeared to affect all fibre groups with a slightly greater effect on the median-sized fibres $(5$ to $8 \mu)$. The result was a general flattening of the histogram. Furthermore, there was a slight general shift to the right with the appearance of fibres above $12 \mu$ external diameter. They may represent swollen fibres in an early stage of degeneration.

FIBRE DIAMETER STUDIES IN SAPHENOUS NERVE The fibre spectrum of this sensory nerve is also unimodal ${ }^{1}$ with a peak frequency at 5 to $6 \mu$. This nerve sometimes sends branches out during its course down the lower leg making it difficult always to obtain a constant total number of fibres in the normal. The maximum number of fibres in the normal $(300 \mathrm{~g}$.) adult rat was found to be between 790 and 890 . Both

${ }^{\mathrm{t}}$ When the fibre diameters are placed into $2 \mu$ groups.

TABLE I

DISTRIBUTION OF NERVE FIBRE SIZES IN POSTERIOR TIBIAL NERVE IN NORMAL AND IN I.N.H.-TREATED RATS

\begin{tabular}{|c|c|c|c|c|c|c|c|c|c|c|c|c|c|}
\hline \multirow[t]{2}{*}{ Rat } & \multirow{2}{*}{$\begin{array}{l}\text { Weight } \\
(g .)\end{array}$} & \multirow{2}{*}{$\begin{array}{l}\text { Total } \\
\text { Fibres }\end{array}$} & \multicolumn{10}{|c|}{ Absolute Fibre Numbers } & \multirow{2}{*}{$\begin{array}{l}\text { Weeks on } \\
\text { I.N.H. }\end{array}$} \\
\hline & & & $1-2 \mu$ & $3-4 ! 2$ & $5-6 \%$ & $7-8 !$ & $9-10 !$ & $11-12 ! \ell$ & $13-14 u$ & $15-16 !$ & $17-18 !$ & $19-20 \mu$ & \\
\hline Normal a & 300 & 2,264 & 48 & 250 & 767 & 855 & 318 & 35 & $\longrightarrow$ & 一 & - & -- & 一 \\
\hline Normal b & 300 & 2,522 & 38 & 181 & 705 & 847 & 687 & 76 & - & - & 一 & - & 一 \\
\hline I.N.H. $50 / \mathrm{a}$ & 275 & 1,789 & 18 & 203 & 635 & 563 & 340 & 10 & 3 & 1 & - & 一 & 3 \\
\hline I.N.H. $52 / \mathrm{b}$ & 285 & 1,781 & 10 & 118 & 469 & 605 & 425 & 162 & 10 & $\longrightarrow$ & - & 一 & 6 \\
\hline I.N.H. $53 / \mathrm{a}$ & 295 & 1.436 & 21 & 206 & 350 & 397 & 336 & 110 & 16 & 2 & $\ldots$ & 一 & 7 \\
\hline I.N.H. $53 / \mathrm{b}$ & 295 & 1.227 & 20 & 115 & 209 & 210 & 243 & 104 & 13 & 1 & - & - & 7 \\
\hline
\end{tabular}


TABLE II

CHANGES IN SAPHENOUS NERVE IN FIBRE NUMBERS AND PROPORTIONS OF FIBRES IN EACH FIBRE-SIZE GROUP

\begin{tabular}{|c|c|c|c|c|c|c|c|c|c|}
\hline \multirow[t]{2}{*}{ Diet } & \multirow{2}{*}{$\begin{array}{l}\text { Number of } \\
\text { Nerves }\end{array}$} & \multirow{2}{*}{$\begin{array}{l}\text { Absolute Fibre } \\
\text { Number (mean) }\end{array}$} & \multicolumn{7}{|c|}{ Percentage of Fibres in Each Group Size (Means) } \\
\hline & & & $1-2 \mu$ & $3-4 \mu$ & $5-6 \mu$ & $7-8 \mu$ & $9-10 \mu$ & $11-12 \mu$ & $13-14 \mu$ \\
\hline $\begin{array}{l}\text { Normal } \\
\text { I.N.H. for } 18 \text { days } \\
\text { I.N.H. for } 6 \text { weeks } \\
\text { I.N.H. for } 7 \text { weeks }\end{array}$ & $\begin{array}{l}4 \\
3 \\
3 \\
2\end{array}$ & $\begin{array}{l}781 \\
435 \\
548 \\
476\end{array}$ & $\begin{array}{l}7 \cdot 1 \\
0 \cdot 8 \\
5 \cdot 0 \\
0\end{array}$ & $\begin{array}{r}23 \cdot 4 \\
15 \cdot 8 \\
31 \cdot 1 \\
9 \cdot 8\end{array}$ & $\begin{array}{l}42 \cdot 9 \\
32 \cdot 4 \\
32 \cdot 8 \\
36 \cdot 8\end{array}$ & $\begin{array}{l}21 \cdot 9 \\
27 \cdot 3 \\
20 \cdot 0 \\
18 \cdot 4\end{array}$ & $\begin{array}{r}4 \cdot 4 \\
19 \cdot 3 \\
10 \cdot 3 \\
6 \cdot 5\end{array}$ & $\begin{array}{l}0 \\
3 \cdot 7 \\
0 \cdot 7 \\
0\end{array}$ & $\begin{array}{l}0 \\
0 \cdot 4 \\
0 \cdot 1 \\
0\end{array}$ \\
\hline
\end{tabular}

by inspection and by counting a severe reduction in fibre numbers was found, affecting particularly the median group ( 5 to $6 \mu$ ), and furthermore there was a slight tendency to a shift to the right noted previously in the posterior tibial nerves. Considered in terms of the proportions of fibres in each size group (Table II) there is a general reduction in the proportions of the smaller sized fibres with a corresponding increase in proportions of the larger fibres in 7 to $8 \mu$ and 9 to $10 \mu$ groups.

The absolute numbers of fibres in the saphenous nerve falls from a mean of five normal nerves of 781 fibres to 435 (mean of three nerves) at 18 days, 548 (mean of three nerves) at six weeks, and 476 (two nerves) at seven weeks. It is thus seen that qualitatively there is definite damage to sensory nerve fibres and quantitatively that there is no significant selection to any fibre size. If anything medium and small sized fibres might be more damaged than large size fibres.

\section{DISCUSSION}

The purpose of this study was to determine whether isoniazid neuropathy showed the same pattern of denervation as was found in the organo-phosphorus neuropathy or not. It can unequivocably be stated from these findings that the patterns of degeneration are dissimilar. In I.N.H. neurotoxicity the degeneration can be found in ventral spinal roots in an early stage at the same time as it is occurring distally; in organo-phosphorus neurotoxicity degeneration is always distal first and is rarely found in the sciatic above the knee in the cat. Nerve fibres of both sensory and motor systems are affected but the largest diameter sensory fibres are frequently spared; the spindle primary sensory fibres are always first and most extensively damaged in organo-phosphorus neurotoxicity. The spinal cord pathways are not affected except in a late stage of the process and then only the posterior columns show changes; in organo-phosphorus neurotoxicity long spinal tracts are constantly damaged. These are primary sensory fibres whose distal components are showing changes earlier in the process. There is in the I.N.H. disease, however, a tendency for the degeneration to be more marked in distal than in proximal fibres. This is less evident in the quadriceps femoris and adductor muscles than it is in the psoas muscle. The latter consistently showed remarkably minor changes by comparison with the limb muscles. The muscles below the knee always showed the most advanced change of any.

While it is not possible to find any points of similarity between I.N.H. and organo-phosphorus neurotoxicity except in so far as fibre length would seem to be of some importance to the process, there is considerable similarity between the pattern of denervation disclosed here and that encountered in the neuropathy occurring in humans that complicates acute intermittent porphyria. Cavanagh and Mellick (1965) found in four cases that distal muscles showed a greater amount of denervation than did proximal muscles, and paraspinal muscles showed only minimal change even when the distal limb muscles were almost totally denervated. Most striking was the relative preservation of primary sensory fibres to muscle spindles in acute porphyria that parallels very closely this feature of I.N.H. neuropathy. Sometimes almost the only surviving nerve fibre in muscle sections in both conditions was this large diameter fibre.

The fibre diameter studies do not give a clear answer as to whether fibres of any particular size were particularly affected. This is in part due to the relatively small range of fibre diameters in this species and the unimodal patterns of the fibre spectrums of the nerves employed for measurement. The overall picture was of a general reduction in numbers of all fibre sizes, with perhaps a greater reduction in numbers of small and medium sized fibres than of large diameter fibres. There was if anything, a tendency for the fibre spectrum to shift to the right, although the suggestion that this is possibly due to swelling of the fibres in early degeneration cannot be gainsaid. There is certainly no evidence for believing that larger diameter fibres are more susceptible than smaller fibres, as is clearly evident in organo-phosphorus neurotoxicity (Cavanagh, 1964a).

The changes in the spinal cord in porphyria 
neuropathy are confined to degeneration of the posterior columns, particularly the gracile tracts (Hierons, 1957) and these occur late in the disease, when degeneration can be found in dorsal spinal roots (Cavanagh and Mellick, 1965). The gracile tracts were similarly affected in I.N.H. animals under the same circumstances, and this must be considered as the result of failure of the proximal axons of sensory root ganglion cells. It is of interest that this occurs later than failure of their distal axons.

One of the most outstanding features of the changes found in muscles in I.N.H. neurotoxicity was the very considerable amount of collateral sprouting from surviving fibres that was constantly present in both adult and young animals. It is clear from this that cells that are not metabolically damaged to the point of degeneration are still capable of actively synthesising new axoplasm. Zbinden and Studer $(1955 \mathrm{~b})$ found that pyridoxine $(50 \mathrm{mg} . / \mathrm{kg}$./ day) gave a substantial degree of protection against the neuropathy and it is probable therefore that I.N.H. is likely to be damaging the nerve cells by virtue of its competitive antagonism to the phosphorylation of pyridoxine (Holtz and Palm, 1964). This would interfere with many transamination and decarboxylation steps which require pyridoxal phosphate as a cofactor. How this type of metabolic lesion produces a pattern of denervation very closely similar to that found in acute intermittent porphyria where the metabolic lesion, according to De Matteis and Rimington (1962), may well be a deficiency in acetate-coenzyme $A$, is not at all clear. The final metabolic path that gives rise to distal degeneration and selects these particular nerve cells must be shared by both these metabolic lesions.

\section{SUMMARY}

Adult and weanling rats have been fed isoniazid ( 250 mg./kg./day) and the resultant pattern of denervation has been studied. While the disturbance predominantly affects motor nerve fibres, particularly in distal muscles, sensory fibres are also extensively damaged. Medium fibre sizes seem to be especially damaged and large diameter sensory fibres are usually spared. The pattern of denervation closely resembles that found associated with acute intermittent porphyria in humans. It is unlike that caused by certain organo-phosphorus compounds.
REFERENCES

Biehl, J. P. (1956). The role of the dose and the metabolic fate of isoniazid in the emergence of isoniazid resistance. Trans. Conf. Chemother. Tuberc. (U.S. Veterans' Admin.), 15, 279-282.

(1957). Emergence of drug resistance as related to the dosage and metabolism of isoniazid. Ibid., 16, 108-113.

-, and Skavlem, J. H. (1953). Toxicity of isoniazid. Amer. Rev. Tuberc., 68, 296-297.

_- and Vilter, R. W. (1954). Effect of isoniazid on vitamin B6 metabolism; its possible signifizanze in producing isoniazid neuritis. Proc. Soc. exp. Biol. (N.Y.), 85, 389-392.

Boone, I. U., and Woodward, K. T. (1953). Relationship of pyridoxine and its derivatives to the mechanism of action of isoniazid. Ibid., 84, 292-296.

Cavanagh, J. B. (1954). The toxiz effests of tri-ortho-cresyl phosphate on the nervous system. J. Neurol. Neurosurg. Psychiat. 17, 163-172.

-(1964a). Peripheral nerve changes in ortho-cresyl phosphate poisoning in the cat. J. Path. Bact., 87, 365-383.

- (1964b). The significance of the 'dying back' process in experimental and human neurological disea se. Int. Rev. exp. Path., 3, 219-267.

_, and Mellick, R.S. (1965). On the nature of the peripheral nerve lesions associated with acute intermittent porphyria. J. Neurol. Neurosurg. Psychiat., 28, 320-327.

- Passingham, R. J., and Vogt, J. A. (1964). Staining of sensory and motor nerves in muscles with sudan black B. J. Path. Bact. 88, 89-92.

- and Patangia, G. N. (1965). Changes in the central nervous system in the cat as the result of tri-o-cresyl phosphate poisoning. Brain, 88, 165-180.

Evans, D. A. P., Manley, K. A., and McKusick, V. A. (1960). Genetic control of isoniazid metabolism in man. Brit. med. J., 2, 485491.

Gammon, G, D., Burge, F. W., and King, G, (1953), Neural toxicity in tuberculous patients treated with isoniazid (isonicotinic acid hydrazide). Arch. Neurol. Psychiat. (Chic.), 70, 64-.

Harris, H. W., Knight, R. A., and Selin, M. J. (1958). Comparison of isoniazid concentrations in the blood of people of Japanese and European descent. Amer. Rev. Tuberc., 78, 944-948.

Hierons, R. (1957). Changes in the nervous system in acute porphyria. Brain, 80, 176-192.

Holtz, P., and Palm, D. (1964). Pharmacological aspects of vitamin B6. Pharmacol. Rev., 16, 113-178.

Jones, W. A., and Jones, G. P. (1953). Peripheral neuropathy due to isoniazid. Lancet, 1, 1073-1074.

Lichstein, H. C. (1955). Mechanism of competitive action of isonicotinic acid hydrazide and vitamin B6. Proc. Soc. exp. Biol. (N.Y.), 88, 519-522.

De Matteis, F., and Rimington, C. (1962). The biochemical disturbance in acute intermittent and experimental porphyria. Lancet, 1, 1332-1334.

Mitchell, R. S., Riemensnider, D. K., Harsch, J. R., and Bell, J. C. (1958). New information on the clinical implications of individual variations in the metabolic handling of antituberculous drugs, particularly isoniazid. Trans. Conf. Chemother. Tuberc. (U.S. Veterans' Admin.), 17, 77-85.

Munck, B. G. (1965). Amino acid transport by the small intestine of the rat. Biochem. biophys. Acta (Amst.), 94, 136-142.

Pegum, J. S. (1952). Nicotinic acid and burning feet. Lancet, 2, 536.

Schlaepfer, W. W., and Hager, H. (1964a). Ultrastructural studies of INH-induced neuropathy in rats. I. Early axonal changes. Amer. J. Path., 45, 209-219.

- - (1964b). II. Alteration and decomposition of the myelin sheath. Ibid., 45, 423-433.

,$--(1964 c)$. III. Repair and regeneration. Ibid., 45, 678-689.

Vial, J. D. (1958). The early changes in the axoplasm during Wallerian degeneration. J. biophys, biochem. Cytol., 4, 551-555

Zbinden, G., and Studer, A. (1955a). Zur Wirkung von Vitaminen der B-Gruppe auf die experimentelle Isoniazid- 'Neuritis'. Schweiz. Z. Path., 18, 1198-1211.

- (1955b). Experimenteller Beitrag zur Frage der IsoniazidNeuritis und Ihrer Beeinflussung durch Pyridoxin. Z. Tuberk., 107, 97-107. 